J. Dairy Sci. 99:1959-1967

http://dx.doi.org/10.3168/jds.2015-10012

(C) 2016, THE AUTHORS. Published by FASS and Elsevier Inc. on behalf

of the American Dairy Science Association ${ }^{\circledR}$. This is an open access article under

the CC BY-NC-ND license (http://creativecommons.org/licenses/by-nc-nd/3.0/).

\title{
Heritability estimates for enteric methane emissions from Holstein cattle measured using noninvasive methods
}

\author{
Jan Lassen ${ }^{1}$ and Peter Løvendahl \\ Centre for Quantitative Genetic and Genomics, Department of Molecular Biology and Genetics, Faculty of Science and Technology, \\ Aarhus University, PO Box 50, DK-8830 Tjele, Denmark
}

\begin{abstract}
The objective of this study was to estimate heritability of enteric methane emissions from dairy cattle. Methane $\left(\mathrm{CH}_{4}\right)$ and $\mathrm{CO}_{2}$ were measured with a portable air-sampler and analyzer unit based on Fourier transform infrared detection. Data were collected on 3,121 Holstein dairy cows from 20 herds using automatic milking systems. Three $\mathrm{CH}_{4}$ phenotypes were acquired: the ratio between $\mathrm{CH}_{4}$ and $\mathrm{CO}_{2}$ in the breath of the cows (CH4_RATIO), the estimated quantified amount of $\mathrm{CH}_{4}$ (in $\left.\mathrm{g} / \mathrm{d}\right)$ measured over a week $(\mathrm{CH} 4$ GRAMSw), and $\mathrm{CH}_{4}$ intensity, defined as grams of $\mathrm{CH}_{4}$ per liter of milk produced (CH4_MILK). Fat- and protein-corrected milk (FPCM) and live weight data were also derived for the analysis. Data were analyzed using several univariate and bivariate linear animal models. The heritability of CH4_GRAMSw and CH4 MILK was 0.21 with a standard error of 0.06 , and the heritability of CH4_RATIO was 0.16 with a standard error of 0.04. The $2 \mathrm{CH}_{4}$ traits CH4_GRAMSw and CH4_RATIO were genetically highly correlated $\left(\mathrm{r}_{\mathrm{g}}=\right.$ 0.83 ) and they were strongly correlated with FPCM, meaning that, in this study, a high genetic potential for milk production will also mean a high genetic potential for $\mathrm{CH}_{4}$ production. The genetic correlation between CH4_MILK and FPCM and live weight showed similar patterns as the other $\mathrm{CH}_{4}$ phenotypes, although the correlations in general were closer to zero. The genetic correlations between the $3 \mathrm{CH}_{4}$ phenotypes and live weight were low and only just significantly different from zero, meaning there is less indication of a genetic relationship between $\mathrm{CH}_{4}$ emission and live weight of the cow. None of the residual correlations between the ratio of $\mathrm{CH}_{4}$ and $\mathrm{CO}_{2}, \mathrm{CH}_{4}$ production in grams per day, FPCM, and live weight were significantly differ-
\end{abstract}

Received June 25, 2015.

Accepted December 1, 2015.

${ }^{1}$ Corresponding author: jan.lassen@mbg.au.dk ent from zero. The results from this study suggest that $\mathrm{CH}_{4}$ emission is partly under genetic control, that it is possible to decrease $\mathrm{CH}_{4}$ emission from dairy cattle through selection, and that selection for higher milk yield will lead to higher genetic merit for $\mathrm{CH}_{4}$ emission/ cow per day.

Key words: methane, dairy cattle, heritability

\section{INTRODUCTION}

Dairy cattle are a major producer of enteric methane emissions (Steinfeld et al., 2006). Methane $\left(\mathrm{CH}_{4}\right)$ is a gas with a greenhouse potential of 25 times that of $\mathrm{CO}_{2}$ (IPCC, 2015). Approximately $90 \%$ of the $\mathrm{CH}_{4}$ produced by dairy cows comes from the breath and eructed rumen gases (Murray et al., 1976); $\mathrm{CH}_{4}$ is also a loss of energy and the product of fermentation by methanogens such as archaea (Hook et al., 2010).

Methods to collect large-scale individual measurements for enteric $\mathrm{CH}_{4}$ production are still in the prototype or experimental phase. Measurements of methane using respiration chambers are expensive and time consuming, which limits the number of data records collected (Ellis et al., 2007; Grainger et al., 2007). Short-term measurements have the potential to produce records from many animals, but each recorded phenotype will lack precision compared with those obtained using the respiration chamber technique. Essentially this will lead to lower heritability but with the potential to make many records.

The sulfur hexafluoride $\left(\mathrm{SF}_{6}\right)$ tracer gas technique can be used for field-scale data collection but requires insertion of rumen boluses, daily animal handling, and laboratory measurement of gases (McGinn et al., 2006). In recent years, researchers have developed many innovative noninvasive techniques, either by infrared (Garnsworthy et al., 2012a; Lassen et al., 2012) or photo acoustic (Negussie et al., 2012) gas analyzers, or by using laser guns (Chagunda et al., 2009). Many of these methods are used to collected noninvasive, short-term spot samples, which makes it possible to obtain records 
while cows are in their normal production environment (Hegarty, 2013).

In precise studies where $\mathrm{CH}_{4}$ has been investigated, a whole-animal respiratory chamber equipment has been used (Ellis et al., 2007). This is the method of choice for physiological and nutritional studies in which a limited number of cows are measured for $\mathrm{CH}_{4}$ emission under controlled conditions. However, for genetic studies on $\mathrm{CH}_{4}$ emission, individual measurements of thousands of cows are necessary (Hayes and Goddard, 2010). That itself makes whole-animal respiratory chamber equipment inappropriate for recordings data for genetic analyses. Furthermore, respiratory chambers are very different from what cows are used to in normal conditions. If cows are taken away from their normal conditions, this will often involve a stress situation, which will influence the cow's DMI, her metabolism, and thereby her performance. Noninvasive methods such as Fourier transform infrared (FTIR) analysis of eructed air is one of many ways to measure $\mathrm{CH}_{4}$ from dairy cattle and is incorporated into the portable measuring unit applied in this project: Gasmet DX-4000 (Gasmet Technologies, Helsinki, Finland; Teye et al., 2009). The FTIR technique uses an infrared transmission spectrum of an air sample, from which an absorbance spectrum can be produced, showing at which infrared wavelengths the sample absorbs (Teye et al., 2009). The spectrum can then be calibrated to provide gas densities in each sample. The current study used the relation between $\mathrm{CH}_{4}$ and $\mathrm{CO}_{2}$ in the breath of the cow (Madsen et al., 2010) as up to $90 \%$ of the ruminant's $\mathrm{CH}_{4}$ production comes from the breath through respiration and eructation of rumination gases (Murray et al., 1976). Using the ratio between $\mathrm{CH}_{4}$ and $\mathrm{CO}_{2}$, together with information on milk yield, live weight, and days carried calf, as a phenotype makes it possible to quantify the amount of $\mathrm{CH}_{4}$ produced per cow because the amount of $\mathrm{CO}_{2}$ can be estimated from production traits such as live weight, milk production, and feed intake (Madsen et al., 2010).

A feature of all systems that measure $\mathrm{CH}_{4}$ online during milking or feeding is that measurements are highly variable. Because several hundred measurements can be made in a very short time, however, individual cow means can be established that are repeatable and related to true emissions. The overwhelming advantage of online techniques, compared with the $\mathrm{SF}_{6}$ and laser detection methods, is the negligible labor requirement facilitated by automation.

Only a few studies have estimated the heritability for enteric $\mathrm{CH}_{4}$ production (Pickering et al., 2015). Several studies, however, have indicated that substantial between-animal variance exists for the trait (Nkrumah et al., 2006; Johnson and Johnson 1995). In general, these studies have used a small number of animals in studies using respiratory chambers or tracer gas $\left(\mathrm{SF}_{6}\right)$ methods. Pickering et al. (2015) showed that when $\mathrm{CH}_{4}$ emissions were measured using a laser gun method, the heritability estimate was 0.05 . In a study of 718 ewes, the heritability for $1-\mathrm{h} \mathrm{CH}_{4}$ production of 0.16 was reported (Robinson et al., 2010); that study also indicated a repeatability of 0.35 . This corresponds to our previous findings in dairy cattle (Lassen et al., 2012).

Taking an indirect approach using $\mathrm{CH}_{4}$ predicted from feed intake, in a study of 548 heifers, a heritability of 0.35 was estimated (de Haas et al., 2011). Another indirect method based on mid-infrared (MIR) spectra showed positive genetic correlations between MIR $\mathrm{CH}_{4}$ in grams per day and fat- and protein-corrected milk yield (FPCM), fat yield, and protein yield (Kandel et al., 2013). This means that a decrease of $\mathrm{CH}_{4}$ should have negative effects on milk, fat, and protein yields. However, for many years, genetic selection has been based on several traits combined in a selection index rather than solely on milk production. Including $\mathrm{CH}_{4}$ emissions in a multi-trait index has gained interest in recent years.

A study has shown that altering selection objectives to target only environmental goals can further enhance the reduction in greenhouse gas emissions at a relatively small economic cost; however, lowering $\mathrm{CH}_{4}$ emissions could come at the price of worse reproduction and health (Wall, 2010).

The primary objective of this study was to estimate the heritability of enteric $\mathrm{CH}_{4}$ emission phenotypes for dairy cows. A secondary objective was to estimate genetic correlations between $\mathrm{CH}_{4}$ phenotypes, FPCM, and live weight based on individual measurements in dairy cows during milking in automatic milking systems.

\section{MATERIALS AND METHODS}

\section{Experimental Design}

A total of 3,121 individual cow $\mathrm{CH}_{4}$ measurements were obtained using an FTIR measuring unit. The cows were measured in 20 herds during their visits to automatic milking systems (AMS). All herds used an indoor feeding strategy without grazing and all cows were fed ad libitum mixed rations with concentrate supplement in the AMS system to attract cows to milking. All herds used a mix of corn and grass silage. Unfortunately, no individual feed intake measures were available on the cows in this study. Herds had between 2 and 8 milking robots. Two different AMS systems were used, the Lely (Lely International N.V., Maassluis, the Netherlands; 1,745 cows) and the DeLaval (DeLaval, Tumba, Sweden; 1,376 cows) systems. In the Lely system, a scale 
that makes individual live weight measurements was installed, which was not the case in the DeLaval AMS system. The FTIR unit air inlet was mounted in the front part of an AMS close to the cow's head for $7 \mathrm{~d}$, recording continuously every $5 \mathrm{~s}$. Data for when cows visited the AMS, as well as available live weight (and milk yield) measurements for each milking were retrieved when the FTIR unit was removed from the herd. Data from the AMS and the FTIR unit were merged so that $\mathrm{CH}_{4}$ measurements matched a visit from a specified cow. Two phenotypes were derived from the data: the mean of the ratio between $\mathrm{CH}_{4}$ and $\mathrm{CO}_{2}$ concentrations (in ppm) from each visit from a cow (CH4_RATIO; Lassen et al., 2012) and the estimated quantified $\mathrm{CH}_{4}$ emission per day based on a calculated emission of $\mathrm{CO}_{2}$ using information on milk yield, live weight, and days carried calf (CH4_GRAMSw; Madsen et al., 2010); CH4_GRAMSw is calculated based on heat-producing units $(\mathbf{H P U})$, which is equal to $\left(5.6 \times\right.$ live weight ${ }^{0.75}+$ $22 \times \mathrm{FPCM}+1.6 \times 10^{-5} \times$ days carried calf). For each HPU, a cow produced $180 \mathrm{~g}$ of $\mathrm{CO}_{2}$ per hour. Thus, CH4_GRAMSw is CH4_RATIO $\times 180 \times 24 \times$ HPU. The CH4_RATIO was available on all cows, whereas CH4_GRAMSw was only available on cows where live weight data were recorded. Milk records were also available on all cows; average daily milk production was extracted from the week in which $\mathrm{CH}_{4}$ records were taken. The fat and protein percentages used were from the closest milk recording made by the national recording organization (RYK, Skejby, Denmark). Fat- and protein-corrected milk was used as phenotype for yield, and was calculated as milk yield $\times(0.25+0.122 \times$ fat $\%+0.077 \times$ protein $\%)$. Live weight was measured at each milking in the Lely AMS. Live weight, FPCM, and CH4_GRAMSw were based on weekly averages, whereas CH4_RATIO was based on each visit in the robot. The third phenotype, CH4_MILK, was calculated as CH4_GRAMSw per FPCM. Cows more than $400 \mathrm{~d}$ in milk were excluded from the analysis.

\section{Statistical Model}

The following linear animal model was used to estimate genetic parameters for CH4_RATIO,

$$
\begin{aligned}
y_{i j} & =\mu+\text { herd }+ \text { month } \times \text { year }+ \text { robot } \times \text { herd }+ \text { lact }_{j} \\
& +\beta \times D I M+\beta \times e^{-0.05} \times D I M \\
& +\sum_{j=1}^{1}(\cos j \theta 2 \pi+\sin j \theta 2 \pi)+a_{i}+p e_{i}+e_{i},
\end{aligned}
$$

where $y$ is the dependent phenotype CH4_RATIO, $\mu$ is the overall intercept, herd is the herd ID where cows were measured, month $\times$ year is the month by year interaction, robot $\times$ herd is the robot by herd interaction accounting for draft winds or similar issues related to a specific robot, lact is the lactation number at recording, and DIM is the days in milk at recording. Days in milk was modeled with a linear regression and a Wilmink term to take changes in early lactation into account. Diurnal variation was modeled using a Fourier series approach previously used by Løvendahl and Bjerring (2006), where $\theta$ is the decimal fraction of the 24 -h diurnal cycle when the breath recording was initiated, (i.e., $\theta=\mathrm{h} / 24)$. The $\beta$ terms are fixed regression coefficients, $a$ terms are the random animal effects, $p e$ terms are the permanent environmental effects, and $e$ is the random residual effect.

The following linear animal model was used to estimate genetic parameters for CH4_GRAMSw:

$$
\begin{aligned}
y_{i j}= & \mu+\text { herd }+ \text { month } \times \text { year }+ \text { robot } \times \text { herd }+ \text { lact }_{j} \\
& +\beta \times D I M+\beta \times e^{-0.05} \times D I M+a_{i}+e_{i},
\end{aligned}
$$

where $y$ is the dependent phenotype CH4_GRAMSw, and the other terms are as previously defined. Days in milk was modeled with a linear regression and a Wilmink term to take changes in early lactation into account. The $\beta$ terms are fixed regression coefficients, $a$ terms are the random animal effects, and $e$ is the random residual effect.

The following linear animal model was used to estimate genetic parameters for FPCM and live weight:

$$
\begin{aligned}
y_{i j}= & \mu+\text { herd }+ \text { month } \times \text { year }+ \text { lact }_{j}+\beta \times \text { DIM } \\
& +\beta \times e^{-0.05} \times D I M+a_{i}+e_{i},
\end{aligned}
$$

where $y$ is the dependent phenotype CH4_MILK, FPCM, or live weight, $\mu$ is the overall intercept, and the other terms are as previously defined. Days in milk was modeled with a linear regression and a Wilmink term to take changes in early lactation into account. The $\beta$ terms are fixed regression coefficients, $a$ terms are the random animal effects, and $e$ is the random residual effect.

The random effects for all models were assumed to be independently and normally distributed with means of zero. $\mathbf{G}_{0}$ is a matrix containing the additive genetic variance; $\mathbf{A}$ is a matrix with the additive genetic relationship of all animals; $\mathbf{P e}_{0}$ is a matrix containing the permanent environmental variance for CH4_RATIO; $\mathbf{R}_{0}$ is a matrix with the residual variance; and $\mathbf{I}$ is the identity matrix containing as many rows and columns as there are records for each trait: 


$$
\operatorname{Var}\left(\begin{array}{c}
\mathbf{a} \\
\mathbf{p e} \\
\mathbf{e}
\end{array}\right) \sim N\left(0,\left\{\begin{array}{ccc}
\mathbf{G}_{0} \otimes \mathbf{A} & 0 & 0 \\
0 & \mathbf{P e}_{0} \otimes \mathbf{I} & 0 \\
0 & 0 & \mathbf{R}_{0} \otimes \mathbf{I}
\end{array}\right\}\right) .
$$

Variance and covariance components were estimated using the average information (AI)REML procedure in DMU (Madsen and Jensen, 2014). Correlations were estimated bivariately between CH4_RATIO, CH4 GRAMSw, FPCM, and live weight, and standard errors were estimated using a Taylor series approximation.

\section{RESULTS}

Basic statistics from the data available are shown in Table 1. Records of CH4_RATIO and FPCM were available for all 3,121 cows, whereas CH4_GRAMSw and live weight were only available for the 1,745 cows measured in Lely milking robots. Each cow had an average of 13.3 visits per week with a standard deviation (SD) of 4.1. Each visit had an average of 95.4 registrations and thereby had a length of $7 \mathrm{~min}$ and $57 \mathrm{~s}$. Mean (SD) CH4_RATIO was 0.087 (0.012). The quantified amount of $\mathrm{CH}_{4}$ was $315 \mathrm{~g} / \mathrm{d}$, ranging from 243 to 518 $\mathrm{g} / \mathrm{d}$. Average daily FPCM yield was $36.6 \mathrm{~kg}$ and the average live weight of the cows in this study was 647 $\mathrm{kg}$, ranging from 467 to $890 \mathrm{~kg}$. A fitted lactation curve based on the solutions from the data is shown in Figure 1. Variance components for the 4 traits CH4_RATIO, CH4_GRAMSw, FPCM, and live weight are shown in Table 2. The repeatability was estimated only for CH4_RATIO because the other traits were analyzed as mean daily production over a weekly performance. The repeatability for CH4_RATIO was 0.35 . Variance components for CH4_RATIO were numerically low but both repeatable (Table 2) and heritable (Table 3). The traits CH4_GRAMSw, FPCM, and live weight showed substantial additive genetic and phenotypic variance (Table 2), which also provides heritability estimates significantly different from zero (Table 3 ). Both CH4_RATIO and CH4_GRAMSw were highly genetically correlated (0.83) and both were genetically

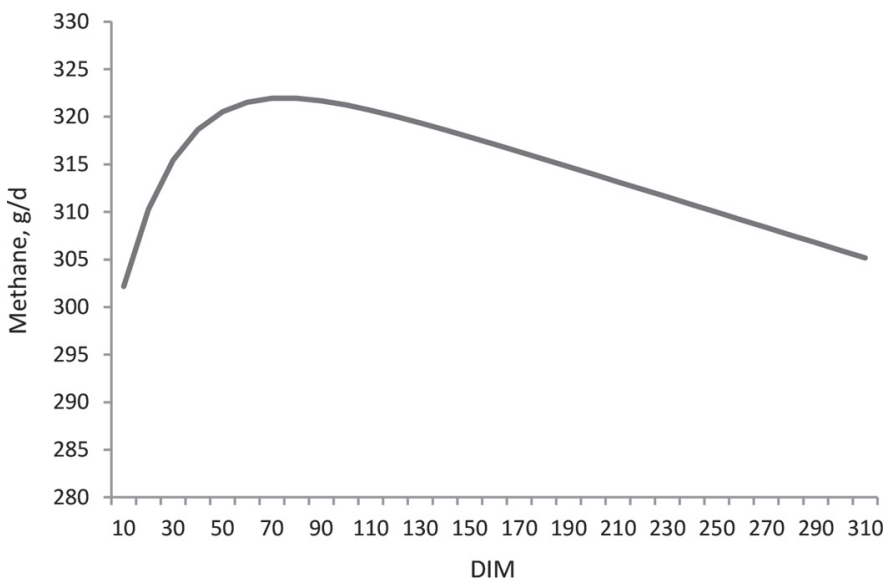

Figure 1. Lactation curve for methane (in grams/day) fitted from model using the solution for DIM.

correlated $\left(\mathrm{r}_{\mathrm{g}}\right)$ with FPCM (CH4_RATIO, $\mathrm{r}_{\mathrm{g}}=0.37$; CH4_GRAMSw, $\left.\mathrm{r}_{\mathrm{g}}=0.43\right)$, meaning that cows with high genetic potential for milk production will also have high genetic potential for $\mathrm{CH}_{4}$ production. Genetic correlation between live weight and CH4_RATIO and CH4_GRAMSw was low but significantly different from zero, meaning that larger cows genetically produce slightly less $\mathrm{CH}_{4}$ than small cows. In general, the residual correlations between the traits were weak.

\section{DISCUSSION}

Few studies have estimated heritabilities for $\mathrm{CH}_{4}$ emission in dairy cattle. This study estimated the heritability for CH4_GRAMSw and CH4_MILK at 0.21 and for CH4_RATIO at 0.16. A heritability of the ratio between $\mathrm{CH}_{4}$ and $\mathrm{CO}_{2}$ of 0.21 was previously documented by Lassen and Løvendahl (2013) from 683 commercial dairy cows.

A significant sire effect was found in an analysis of $\mathrm{CH}_{4}$ emissions during milking in 215 cows (Garnsworthy et al., 2012b), which suggests that there is a genetic component. Also, repeatability, defined as the animal variance not corrected for pedigree, was between 0.35

Table 1. Descriptive statistics such as units, number of cows, mean, standard deviation (SD), and minimum and maximum values for ratio between $\mathrm{CH}_{4}$ and $\mathrm{CO}_{2}\left(\mathrm{CH} 4 \_\mathrm{RATIO}\right)$, daily $\mathrm{CH}_{4}$ production (CH4_GRAMSw), fat- and protein-corrected milk (FPCM), and live weight ${ }^{1}$

\begin{tabular}{lcccccc}
\hline Trait & Unit & No. of cows & Mean & SD & Minimum & Maximum \\
\hline CH4_RATIO & & 3,121 & 0.087 & 0.012 & 0.043 & 0.109 \\
CH4_GRAMSw & g/d & 1,745 & 315 & 36.2 & 243 & 518 \\
CH4_MILK & g/L & 1,745 & 8.61 & 1.15 & 7.23 & 12.1 \\
FPCM & L/d & 3,121 & 36.6 & 7.9 & 19.2 & 62.7 \\
Live weight & $\mathrm{kg}$ & 1,745 & 647 & 68.4 & 467 & 890 \\
\hline
\end{tabular}

${ }^{1}$ CH4_GRAMSw, CH4_MILK (CH4_GRAMSw/FPCM), FPCM, and live weight were based on weekly averages. 
Table 2. Additive genetic variance (a), permanent environmental variance (pe), residual variance (e), phenotypic variance (p), and repeatability for ratio between $\mathrm{CH}_{4}$ and $\mathrm{CO}_{2}\left(\mathrm{CH} 4 \_\mathrm{RATIO}\right)$, daily $\mathrm{CH}_{4}$ production (CH4_GRAMSw), fat- and protein-corrected milk (FPCM), and live weight

\begin{tabular}{lccccc}
\hline & \multicolumn{3}{c}{ Variance } & \\
\cline { 2 - 4 } Trait & $\mathrm{a}$ & $\mathrm{pe}$ & $\mathrm{e}$ & $\mathrm{p}$ & Repeatability \\
\hline CH4_RATIO & 0.0000240 & 0.0000285 & 0.0000975 & 0.00015 & 0.35 \\
CH4_GRAMSw & 274.19 & & $1,037.25$ & $1,311.44$ & \\
CH4_MILK ${ }^{1}$ & 0.32 & 1.20 & 1.52 & \\
FPCM & 16.95 & 45.83 & 62.78 & \\
Live weight & $1,635.46$ & $3,037.29$ & $4,672.75$ & \\
${ }^{1}$ CH4_MILK = CH4_GRAMSw/FPCM. & & & & \\
\end{tabular}

and 0.40 in a study of 50 Holstein and 43 Jersey cows in a Danish study (Lassen et al., 2012). The majority of the studies performed to date have been on Holstein cows but there are also studies on Finnish Ayrshire (Negussie et al., 2012).

Precise and preferably cheap phenotypes are needed to make genetic evaluations appropriate for traits of interest. For $\mathrm{CH}_{4}$ production, several phenotypes have been suggested (Herd et al., 2013). The first phenotype is $\mathrm{CH}_{4}$ production (MetP) measured in grams or grams/day. The obvious problem selecting for this trait is that it is highly correlated with feed intake and therefore the production trait of interest; in dairy, it is correlated with milk production and in sheep or beef, it is correlated with meat production. To handle this, precise and meaningful economic values are extremely important in the selection index used. One option is also to look at $\mathrm{CH}_{4}$ yield (MetY), defined as grams of $\mathrm{CH}_{4}$ / kilogram of DMI, or as $\mathrm{CH}_{4}$ intensity (MetI), defined as grams of $\mathrm{CH}_{4}$ per kilogram of milk produced per day. Residual $\mathrm{CH}_{4}$ production, defined as observed minus predicted $\mathrm{CH}_{4}$ production, has been suggested as a useful phenotype (Herd et al., 2014). It is essentially based on the same concept as residual feed intake, where the phenotype of interest is regressed for whatever factors influence this phenotype; for example, milk production, live weight, or BCS. For $\mathrm{CH}_{4}$, this could be, for example, milk production, live weight, or feed intake. It is not necessarily obvious which of these phenotypes to select for and it is essential to ensure that correlated information is available so that a decline in other traits is avoided when selecting for the chosen $\mathrm{CH}_{4}$ phenotype. It might be that the most correct way is to use MetP and include the correlation structure with milk yield. In a study on beef cattle, genetic correlations between live weight and the CH4 phenotypes-MetP (0.79), MetY (0.18), and MetI ( -0.23$)$ - suggests that very different responses will be obtained in the production trait depending on which $\mathrm{CH}_{4}$ phenotype is selected for (Donoghue et al., 2013). The same study also reports genetic correlations between MetP, MetY, and MetI ranging from 0.87 to 0.96 , so it could be argued that using one or the other trait would have a limited effect on the correlated response in the production trait. However, because the current study published preliminary results, much more work and collaboration is needed in this field.

In this study, concentrations of $\mathrm{CH}_{4}$ and $\mathrm{CO}_{2}$ measured were used to predict daily MetP through predicted $\mathrm{CO}_{2}$ production based on the live weight of the fetus, the milk yield, and heat production (Madsen et al., 2010). This method ignores whatever animal variation there might be in $\mathrm{CO}_{2}$ production but has been shown to yield results as precise as though obtained from $\mathrm{SF}_{6}$ methodology or respiration chamber techniques (Haque et al., 2014). It cannot be ignored that animals differing in methane emission or milk production might also differ in individual digestibility of the

Table 3. Heritability (diagonal), residual correlation (below diagonal), and additive genetic correlation (above diagonal) for ratio between $\mathrm{CH}_{4}$ and $\mathrm{CO}_{2}$ (CH4_RATIO), daily $\mathrm{CH}_{4}$ production (CH4_GRAMSw), fat- and protein-corrected milk (FPCM), and live weight (means $\pm \mathrm{SE}$ )

\begin{tabular}{lrrrrr}
\hline Trait & CH4_RATIO & CH4_GRAMSW & CH4_MILK & FPCM & \multicolumn{1}{c}{ Live weight } \\
\hline CH4_RATIO & $0.16 \pm 0.04$ & $0.83 \pm 0.14$ & $0.23 \pm 0.10$ & $0.37 \pm 0.07$ & $-0.16 \pm 0.07$ \\
CH4_GRAMSw & $0.18 \pm 0.11$ & $0.21 \pm 0.06$ & $0.07 \pm 0.09$ & $0.43 \pm 0.10$ & $-0.18 \pm 0.08$ \\
CH4_MILK & $0.21 \pm 0.06$ & $0.11 \pm 0.06$ & $0.21 \pm 0.06$ & $0.15 \pm 0.09$ & $-0.10 \pm 0.08$ \\
FPCM & $0.04 \pm 0.06$ & $0.12 \pm 0.08$ & $0.21 \pm 0.04$ & $0.27 \pm 0.03$ & $-0.10 \pm 0.09$ \\
Live weight & $-0.12 \pm 0.08$ & $-0.05 \pm 0.07$ & $-0.05 \pm 0.07$ & $0.04 \pm 0.08$ & $0.35 \pm 0.05$ \\
\hline
\end{tabular}

${ }^{1} \mathrm{CH} 4 \_$MILK $=$CH4_GRAMSw/FPCM. 
feed (Knapp et al., 2014). Moreover, heritability might be due in part to the heritability of FPCM and live weight, because both used to estimate methane production. Still, the CH4_RATIO is heritable, so the data on methane emission do contain some genetic component. More work is needed to obtain methane phenotypes from sniffer data that is independent of other traits, including feed intake.

de Haas et al. (2011) reported a heritability of 0.35 for predicted $\mathrm{CH}_{4}$ emissions in Dutch cows; predicted $\mathrm{CH}_{4}$ emissions were derived from feed intake and maintenance and therefore likely to be heritable given the heritability of DMI and live weight (Berry and Crowley, 2013). Genetic parameters for total $\mathrm{CH}_{4}$ production and $\mathrm{CH}_{4}$ yield measured in respiration chambers at fixed levels of feed intake have been reported for sheep (Pinares-Patiño et al., 2013) and beef cattle (Donoghue et al., 2013). The heritability (SE) for total $\mathrm{CH}_{4}$ production in sheep and beef cattle was $0.29(0.05)$ and 0.40 (0.11), respectively. Heritability (SE) estimates in sheep and beef for $\mathrm{CH}_{4}$ emissions per kilogram of feed intake were $0.13(0.03)$ and $0.19(0.10)$, respectively. The coefficient of genetic variation for both $\mathrm{CH}_{4}$ traits in sheep ranged from 0.10 to 0.13 , suggesting that genetic variation does indeed exist. Milk fatty acid composition has also been suggested as a means of predicting enteric $\mathrm{CH}_{4}$ output in lactating dairy cattle because of the common biochemical pathways among $\mathrm{CH}_{4}$, acetate, and butyrate in the rumen. A stoichiometric relationship between $\mathrm{CH}_{4}$ and ruminal acetate, propionate, and butyrate was proposed by Demeyer and Van Nevel (1975). These short-chain fatty acids formed in the rumen in particular act as precursors for the de novo synthesis of milk fatty acids in the mammary tissue. Predictive $\mathrm{CH}_{4}$ equations from milk fatty acid composition in dairy cows have been developed in several studies (Chilliard et al., 2009; Dijkstra et al., 2011). Kandel et al. (2013) reported heritability estimates of 0.34 to 0.37 for predicted $\mathrm{CH}_{4}$ emissions in dairy cows based on milk fatty acid composition. However, such estimates based on predicted $\mathrm{CH}_{4}$ are heavily smoothed and based on traits that already have high heritability, so they are expected to have high heritability themselves.

No matter how good a proxy measure is, it would be preferable to have real measurements. The strength of any indicator will always rely on how well the indicator is measured and how well the breeding goal trait is defined. Many of the techniques developed today to record $\mathrm{CH}_{4}$ phenotypes in dairy cattle are based on short-term measurements and thus only a snapshot of the dairy cow's full biology is observed (Garnsworthy et al., 2012a; Lassen et al., 2012; Negussie et al., 2012).
Bell et al. (2014) showed that using the $\mathrm{CH}_{4} / \mathrm{CO}_{2}$ ratio can give highly repeatable measurements (0.59) for methane emission and could be used to rank animals for genetic evaluations. It is important to be aware of this when generating the phenotypes (Hegarty, 2013); several factors, such as time of day, year, lactation stage, herd, feed composition, and so on, affect MP. Therefore, to predict daily MP or lactational MetP, it is necessary to correct for these factors to reduce bias in the phenotype and in the genetic prediction or estimation of variance components.

\section{Relationship with Feed Intake and Milk Production}

Feed intake, diet composition, BW, activity, circadian rhythm, stage of lactation, and inter-individual differences are major factors influencing $\mathrm{CH}_{4}$ production. Because of these considerable variations, it is difficult but very important to obtain reliable estimates from single $\mathrm{CH}_{4}$ measurements that reflect entire daily $\mathrm{CH}_{4}$ production. This problem calls for establishing relationships between snapshot $\mathrm{CH}_{4}$ concentrations determined once or twice a day and total daily $\mathrm{CH}_{4}$ production. One way to overcome this might be to measure the ratio between $\mathrm{CH}_{4}$ and $\mathrm{CO}_{2}$ (Madsen et al., 2010).

We found positive genetic correlations between milk production and $\mathrm{CH}_{4}$ production, which probably reflects the relationship between energy intake, $\mathrm{CH}_{4}$ production, and milk production. Berry (2013) cautioned about inferring heritability estimates from $\mathrm{CH}_{4}$ emissions per unit feed intake (or any $\mathrm{CH}_{4}$ phenotype that includes known heritable traits in the numerator or denominator). Berry (2013) simulated individual animal daily $\mathrm{CH}_{4}$ emissions for a data set of growing bulls used previously in the estimation of variance components of feed efficiency by Crowley et al. (2010). Methane yield was defined as predicted daily $\mathrm{CH}_{4}$ emissions divided by daily feed intake. Berry (2013) reported an (expected) heritability of zero for simulated daily $\mathrm{CH}_{4}$ emissions but a heritability of $0.19(0.05)$ for predicted $\mathrm{CH}_{4}$ yield. The existence of a significant heritability of predicted $\mathrm{CH}_{4}$ yield was an artifact, not of heritable variation in $\mathrm{CH}_{4}$ emissions but because the heritability of feed intake was 0.49 (Crowley et al., 2010). A favorable association between feed efficiency and $\mathrm{CH}_{4}$ production is expected given that $\mathrm{CH}_{4}$ production represents a sink of energy loss (Johnson and Johnson, 1995) and therefore inefficiency.

No data on feed intake were available in this study. Feed intake is strongly correlated with residual feed intake (RFI; Berry and Crowley, 2012) and, as evidenced by the lack of differences in $\mathrm{CH}_{4}$ per unit intake between animals divergent in RFI (Jones et al., 
2011; Arthur et al., 2014), the cause and effect of the observed association between $\mathrm{RFI}$ and $\mathrm{CH}_{4}$ emissions needs to be elucidated. Using the correlations of 0.44 and 0.38 between daily $\mathrm{CH}_{4}$ production and RFI and DMI, respectively, as well as the mean correlation of 0.72 between RFI and DMI from the meta-analysis of Berry and Crowley (2012), 26\% of the phenotypic variation in daily $\mathrm{CH}_{4}$ production could be explained by RFI after accounting for differences in feed intake. However, this needs further investigation. Nonetheless, advocating selection on RFI should be undertaken with caution because reducing feed intake, even if production is held constant, may reduce $\mathrm{CH}_{4}$ emissions per day, but unless appropriately addressed within the breeding goal, may result in greater negative energy balance and more body tissue mobilization in lactating cows (McParland et al., 2014). More severe and prolonged negative energy balance in early lactation is known to have unfavorable consequences for dairy cow health and fertility (Roche et al., 2009), thereby negating or even increasing $\mathrm{CH}_{4}$ emissions within the herd or entire dairy sector.

Methane production depends, in part, upon the quantity of feed consumed, although this effect is moderated by feed digestibility and other feed and animal characteristics, such as composition of the diet and dietary fat (Hegarty, 2009). The feeding efficiency (i.e., RFI) of the animal may also have an effect, with low-RFI cattle eating less than expected in relation to their live weight and growth rate. By comparing the $\mathrm{CH}_{4}$ emissions of beef cattle chosen from breeding lines divergently selected for RFI, Herd et al. (2014) found that the most efficient animals (low RFI) had a lower $\mathrm{CH}_{4}$ production rate. The association between RFI and $\mathrm{CH}_{4}$ emission was also shown by Nkrumah at al. (2006), where $\mathrm{CH}_{4}$ production was $28 \%$ less in low-RFI animals compared with high-RFI animals.

The positive genetic correlation between predicted $\mathrm{CH}_{4}$ emission and RFI (phenotypic correlation: 0.72; genetic correlation: 0.32) suggests that selection on RFI may be one strategy to reduce $\mathrm{CH}_{4}$ emissions from ruminants (de Haas et al., 2011). Accounting for just one of these components might, however, result in undesirable genetic changes. Particular consideration must be given to a general involvement of RFI in selection strategies of dairy cows because, in early lactation, dairy cows ingest insufficient feed to meet energy requirements for milk production and thus enter into a negative energy balance. Severe and prolonged negative energy balance is associated with infertility in dairy cows, which increases $\mathrm{CH}_{4}$ emissions at the herd level because of the increased animal numbers needed to sustain a given milk production (Garnsworthy, 2004).

\section{MIR Spectra}

Using MIR spectra to predict other phenotypes is indeed appealing. The phenotypic and genetic variability of $\mathrm{CH}_{4}$ production $(\mathrm{g} / \mathrm{d})$ and $\mathrm{CH}_{4}$ intensity $(\mathrm{g} / \mathrm{kg}$ of FPCM) has been predicted by MIR. However, such estimates based on predicted $\mathrm{CH}_{4}$ are heavily smoothed and based on traits that already have high heritability, so they are expected to have high heritability themselves. Kandel et al. (2013) estimated genetic parameters of $\mathrm{MIR} \mathrm{CH}_{4}$ traits by using single-trait random regression test-day models from 679,444 test-day records collected from Holstein cows in their first 3 lactations. The calculated heritability values were around 0.10 for $\mathrm{CH}_{4}$ in grams per day $(0.12,0.10$, and 0.09 for first, second, and third parity, respectively). The $\mathrm{CH}_{4}$ intensity had slightly higher heritability with values around 0.15 $(0.18,0.12$, and 0.14 for cows in their first 3 lactations, respectively). These results suggest a moderate heritability of $\mathrm{CH}_{4}$ emission by dairy cows.

The positive genetic correlations observed between CH4_GRAMSw and FPCM were also found in a study based on MIR $\mathrm{CH}_{4}$ in grams/day (Kandel et al., 2013). Here, the authors found a positive genetic correlation between MIR $\mathrm{CH}_{4}$ in grams/day and FPCM, fat yield, and protein yield. This means that a decrease of $\mathrm{CH}_{4}$ should have negative effects on milk, fat, and protein yields and vice versa if $\mathrm{CH}_{4}$ is expressed per kilogram of milk. However, for many years, genetic selection has been based on several traits combined in a selection index rather than solely on milk production. Studying the effect of the introduction of $\mathrm{MIR} \mathrm{CH}_{4}$ trait in the breeding selection index is therefore interesting. Kandel et al. (2014) studied the consequences of selection for environmental impact traits in dairy cows. The authors used $\mathrm{CH}_{4}$ intensity ( $\mathrm{g}$ of $\mathrm{CH}_{4}$ per $\mathrm{kg}$ of milk) and calculated several approximate genetic correlations from estimated breeding values to other traits. Negative approximate genetic correlations were observed between $\mathrm{CH}_{4}$ intensity and milk yield $(-0.67)$, fat yield $(-0.13)$, protein yield $(-0.46)$, longevity $(-0.07)$, and average of conformation traits $(-0.23)$. Positive approximate correlations were observed for fertility (0.31) and BCS (0.27). Based on these correlations and by putting a hypothetical $25 \%$ weight on $\mathrm{CH}_{4}$ intensity on the current Walloon genetic evaluation index and a proportional reduction on other selection traits, the response to selection was a reduction of $\mathrm{CH}_{4}$ intensity by $24 \%$, and increases in milk yield by $30 \%$, fat yield by $17 \%$, protein yield by $29 \%$, SCS by $-15 \%$, longevity by $24 \%$, fertility by $-11 \%$, BCS by $-13 \%$, and conformation traits by $24 \%$. These results suggest that a decrease of $\mathrm{CH}_{4}$ intensity could have a negative effect on cow fertil- 
ity but a positive effect on longevity, but this needs to be tested on independent data as well as on data where more $\mathrm{CH}_{4}$ observations are available.

\section{CONCLUSIONS}

Measurements of $\mathrm{CH}_{4}$ were made during milking in AMS using an FTIR approach. Based on these data, we conclude that estimated enteric $\mathrm{CH}_{4}$ emission from dairy cattle is a heritable trait. The estimate in this study was 0.21 (SE 0.06) for CH4_GRAMSw and CH4_MILK, with these estimates being significantly different from zero. Methane emission, as defined in this study, was positively correlated with fat- and proteincorrected milk, meaning that selecting for higher milk production will also increase $\mathrm{CH}_{4}$ emission.

\section{ACKNOWLEDGMENTS}

This study was financed by the Independent Danish Research Council | Technology and Production (Copenhagen, Denmark; project number 11-105913). The authors are grateful to the 21 commercial herds for providing access to cows and data for this study.

\section{REFERENCES}

Arthur, P. F., J. E. Pryce, and R. M. Herd. 2014. Lessons learnt from 25 years of feed efficiency research in Australia. In Proc. 10th World Congress on Genetics Applied to Livestock Production (WCGALP), Vancouver, Canada. Am. Soc. Anim. Sci., Champaign, IL.

Bell, M. J., N. Saunders, R. H. Wilcox, E. M. Homer, J. R. Goodman, J. Craigon, and P. C. Garnsworthy. 2014. Methane emissions among individual dairy cows during milking quantified by eructation peaks or ratio with carbon dioxide. J. Dairy Sci. 97:6536-6546.

Berry, D. P. 2013. Breeding strategies to reduce environmental footprint in dairy cattle. Adv. Anim. Biosci. 4:28-36.

Berry, D. P., and J. J. Crowley. 2012. Residual intake and body weight gain: A new measure of efficiency in growing cattle. J. Anim. Sci. 90:109-115.

Berry, D. P., and J. J. Crowley. 2013. Genetics of feed efficiency in dairy and beef cattle. J. Anim. Sci. 91:1594-1613.

Chagunda, M. G. G., D. Ross, and D. J. Roberts. 2009. On the use of a laser methane detector in dairy cows. Comput. Electron. Agric. $68: 157-160$.

Chilliard, Y., C. Martin, J. Rouel, and M. Doreau. 2009. Milk fatty acids in dairy cows fed whole crude linseed, extruded linseed, or linseed oil, and their relationship with methane output. J. Dairy Sci. 92:5199-5211.

Crowley, J. J., M. McGee, D. A. Kenny, D. H. Crews, R. D. Evans, and D. P. Berry. 2010. Phenotypic and genetic parameters for different measures of feed efficiency in different breeds of Irish performance tested beef bulls. J. Anim. Sci. 88:885-894.

de Haas, Y., J. J. Windig, M. P. L. Calus, J. Dijkstra, M. de Haan, A. Bannink, and R. F. Veerkamp. 2011. Genetic parameters for predicted methane production and potential for reducing enteric emissions through genomic selection. J. Dairy Sci. 94:6122-6134.

Demeyer, D. I., and C. J. Van Nevel. 1975. Methanogenesis, an integrated part of carbohydrate fermentation and its control. Pages 366-382 in Digestion and Metabolism in the Ruminant. I. W. McDonald and A. C. I. Warner, ed. The University of New England Publishing Unit, Armidale, NSW, Australia.
Dijkstra, J., S. M. van Zijderveld, J. A. Apajalahti, A. Bannink, W. J. J. Gerrits, J. R. Newbold, H. B. Perdok, and H. Berends. 2011. Relationships between methane production and milk fatty acid profiles in dairy cattle. Anim. Feed Sci. Technol. 166-67:590-595.

Donoghue, K. A., R. M. Herd, S. H. Bird, P. F. Arthur, and R. F. Hegarty. 2013. Preliminary genetic parameters for methane production in Australian beef cattle. Pages 290-293 in 20th Proc. Assoc. Advmt. Anim. Breed. Genet. Association for the Advancement of Animal Breeding and Genetics, Australia.

Ellis, J. L., E. Kebreab, N. E. Odongo, B. W. McBride, E. K. Okine, and J. France. 2007. Prediction of methane production from dairy and beef cattle. J. Dairy Sci. 90:3456-3466.

Garnsworthy, P. C. 2004. The environmental impact of fertility in dairy cows: A modelling approach to predict methane and ammonia emissions. Anim. Feed Sci. Technol. 112:211-223.

Garnsworthy, P. C., J. Craigon, J. H. Hernandez-Medrano, and N. Saunders. 2012a. On-farm methane measurements during milking correlate with total methane production by individual dairy cows. J. Dairy Sci. 95:3166-3180.

Garnsworthy, P. C. J. Craigon, J. H. Hernandez-Medrano, and N. Saunders. 2012b. Variation among individual dairy cows in methane measurements made on farm during milking. J. Dairy Sci. 95:3181-3189

Grainger, C., T. Clarke, S. M. McGinn, M. J. Auldist, K. A. Beauchemin, M. C. Hannah, G. C. Waghorn, H. Clark, and R. J. Eckard. 2007. Methane emissions from dairy cows measured using the sulfur hexafluoride $\left(\mathrm{SF}_{6}\right)$ tracer and chamber techniques. J. Dairy Sci. 90:2755-2766.

Haque, M. N., C. Cornou, and J. Madsen. 2014. Estimation of methane emission using the $\mathrm{CO} 2$ method from dairy cows fed concentrate with different carbohydrate compositions in automatic milking system. Livest. Sci. 164:57-66.

Hayes, B., and M. Goddard. 2010. Genome-wide association and genomic selection in animal breeding. Genome 53:876-883.

Hegarty, R. S. 2009. Current and emerging technologies for decreasing enteric methane emission from individual ruminants. Rec. Adv. Anim. Nutr. 17:81-88.

Hegarty, R. S. 2013. Applicability of short-term emission measurements for on-farm quantification of enteric methane. Animal $7: 401-408$

Herd, R. M., P. F. Arthur, S. H. Bird, K. A. Donoghue, and R. S. Hegarty. 2014 Genetic variation for methane traits in beef cattle. In 10th World Congress on Genetics Applied to Livestock Production (WCGALP), Vancouver, Canada.

Herd, R. M., S. H. Bird, K. A. Donoghue, P. F. Arthur, and R. S. Hegarty. 2013. Phenotypic associations between methane production traits, volatile fatty acids and animal breeding traits. Pages 286-289 in Proc. Assoc. Advmt. Anim. Breed. Genet. (AAABG), Napier, New Zealand.

Hook, S. E., A. D. Wright, and B. W. McBride. 2010. Methanogens: Methane producers of the rumen and mitigation strategies. Archaea 2010:945785. http://dx.doi.org/10.1155/2010/945785.

IPCC. 2015. Climate Change 2007: Mitigation of Climate Change. Accessed Aug. 13, 2015. http://www.ipcc.ch/publications_and_ data/publications_ipcc_fourth_assessment_report_wg3_report_ mitigation_of_climate_change.htm .

Johnson, K. A., and D. E. Johnson. 1995. Methane emissions from cattle. J. Anim. Sci. 73:2483-2492.

Jones, F. M., F. A. Phillips, T. Naylor, and N. B. Mercer. 2011. Methane emissions from grazing Angus beef cows selected for divergent residual feed intake. Anim. Feed Sci. Technol. 166-167:302-307.

Kandel, P. B., S. Vanderick, M.-L. Vanrobays, A. Vanlierde, F. Dehareng, E. Froidmont, H. Soyeurt, and N. Gengler. 2014. Consequences of selection for environmental impact traits in dairy cows. In 10th World Congress on Genetics Applied to Livestock Production (WCGALP), Vancouver, Canada. Am. Soc. Anim. Sci. Champaign, IL.

Kandel, P. B., M.-L. Vanrobays, A. Vanlierde, F. Dehareng, E. Froidmont, P. Dardenne, E. Lewis, F. Buckley, M. H. Deighton, S. McParland, N. Gengler, and H. Soyeurt. 2013. Genetic parameters for methane emissions predicted from milk mid-infrared spectra in 
dairy cows. Page 279 in Proc. Adv. Anim. Biosci. (5th Greenhouse Gases Animal Agriculture Conference). Cambridge Journals, Cambridge, UK.

Knapp, J. R., G. L. Laur, P. A. Vadas, W. P. Weiss, and J. M. Tricarico. 2014. Invited review: Enteric methane in dairy cattle production: Quantifying the opportunities and impact of reducing emissions. J. Dairy Sci. 97:3231-3261.

Lassen, J., and P. Løvendahl. 2013. Heritability for enteric methane emission from Danish Holstein cows using a non-invasive FTIR method. Adv. Anim. Biosci. 4:280. (Abstr.)

Lassen, J., P. Løvendahl, and J. Madsen. 2012. Accuracy of non-invasive breath methane measurements using Fourier Transformed Infrared methods on individual cows. J. Dairy Sci. 95:890-898.

Løvendahl, P., and M. Bjerring. 2006. Detection of carryover in automated milk sampling equipment. J. Dairy Sci. 89:3645-3652.

Madsen, J., B. S. Bjerg, T. Hvelplund, M. R. Weisbjerg, and P. Lund. 2010. Methane and carbon dioxide ratio in excreted air for quantification of methane production in ruminants. Livest. Sci. 129:223227.

Madsen, P., and J. Jensen. 2014. A User's Guide to DMU, version 6, release 5.0. Aarhus University, Faculty of Agricultural Sciences Denmark.

McGinn, S. M., K. A. Beauchemin, A. D. Iwaasa, and T. A. McAllister. 2006. Assessment of the sulfur hexafluoride (SF6) tracer technique for measuring enteric methane emissions from cattle. J. Environ. Qual. 35:1686-1691.

McParland, S., E. Kennedy, S. Butler, M. O'Donovan, B. McCarthy, J. E. Pryce, and D. P. Berry. 2014. Mid-infrared spectroscopy to predict feed intake and efficiency in lactating dairy cows. In 10th World Congress on Genetics Applied to Livestock Production (WCGALP), Vancouver, Canada. Am. Soc. Anim. Sci., Champaign, IL.

Murray, R. M., A. M. Bryant, and R. A. Leng. 1976. Rates of production of methane in rumen and large-intestine of sheep. Br. J. Nutr. $36: 1-14$.

Negussie, E., A.-E. Liinamo, P. Mantysaari, E. Mantysaari, and M. Lidauer. 2012. Between and within-individual variation in methane output measurements in dairy cows. Page 170 in European Association of Animal Production, Bratislava, Slovakia. Wageningen Academic Publishers, Wageningen, the Netherlands.

Nkrumah, J. D., E. K. Okine, G. W. Mathison, K. Schmid, C. Li, J. A. Basarab, M. A. Price, Z. Wang, and S. S. Moore. 2006. Relationships of feedlot feed efficiency, performance, and feeding behavior with metabolic rate, methane production, and energy partitioning in beef cattle. J. Anim. Sci. 84:145-153.

Pickering, N. K., M. G. G. Chagunda, G. Banos, R. Mrode, J. C. McEwan, and E. Wall. 2015. Genetic parameters for predicted methane production and laser methane detector measurements. J. Anim. Sci. 93:11-20.

Pinares-Patiño, C. S., S. M. Hickey, E. A. Young, K. G. Dodds, S. MacLean, G. Molano, E. Sandoval, H. Kjestrup, R. Harland, N. K. Pickering, and J. C. McEwan. 2013. Heritability estimates of methane emissions from sheep. Animal 7:316-321.

Robinson, D. L., J. P. Goopy, R. S. Hegarty, and P. E. Vercoe. 2010. Repeatability, animal and sire variation in 1-hr methane emissions and relationship with rumen volatile fatty acid concentrations. Abstract 712 in Proc. 9th World Congress in Genetics Applied to Livestock. German Society of Animal Science, Giessen, Germany.

Roche, J. R., Jr., N. C. Friggens, J. K. Kay, M. W. Fisher, K. J. Stafford, and D. P. Berry. 2009. Body condition score and its association with dairy cow productivity, health, and welfare. J. Dairy Sci 92:5769-5801.

Steinfeld, H., P. Gerber, T. Wassenaar, V. Castel, M. Rosales, and C. de Haan. 2006. Livestock's long shadow-Environmental issues and options. FAO, United Nations, Rome, Italy.

Teye, F. K., E. Alkkiomaki, A. Simojoki, M. Pastell, and J. Ahokas. 2009. Instrumentation, measurement and performance of three air quality measurement systems for dairy buildings. Appl. Eng. Agric. 25:247-256.

Wall, E. 2010. Broadening breeding goals in a changing world. Abstract no. 41 in Proc. 9th World Congress in Genetics Applied to Livestock Production. German Society of Animal Science, Giessen, Germany. 